CHAPTER 13

\title{
The Enabling Environments for the Digitalization of African Agriculture
}

\author{
Heike Baumüller and Benjamin K. Addom
}


T he slow pace of modernization in Africa's agricultural sector contributes to persistent poverty and deteriorating food security on the continent. To prevent Africa's food import bill from surging to a predicted US $\$ 110$ billion by 2025, Africa's agricultural sector must transform (AGRA 2017). Numerous challenges remain to be addressed. An Intergovernmental Panel on Climate Change report from 2014 identifies Africa as a region that is and will increasingly be profoundly affected by climate change (Niang et al. 2014). This is partly due to African agriculture's heavy reliance on rainfed systems, which account for approximately 90 percent of crop production across the continent on existing low-producing arable land. In the past five years alone, African countries have faced extreme droughts and floods, prolonged by rising temperatures (WMO 2020), all of which have brought yield losses and hard times for rural families. This already vulnerable food system now faces even greater risk due to the COVID-19 pandemic currently gripping the world, threatening to bring a global food shortage and new hunger crises (Hernandez et al. 2020). In a typical year, postharvest losses are as high as 27 percent, resulting in decreasing productivity within the agricultural system, and access to intraregional and global markets by farmers and traders is often poor (Christiaensen and Demery 2018). These conditions affect Africa's economic potential to absorb its un- and underemployed population, some 60 percent of whom are youth (Ighobor 2013), and better integrate women into higher levels of the value chain.

At the same time, however, digitalization is effecting change and driving development across all sectors, including agriculture. Digitalization is reducing barriers, facilitating collaboration, and generating opportunities for inclusion, thereby contributing to the achievement of the United Nations Sustainable Development Goals. Within the agricultural sector, digitalization is viewed as a game changer in building climate resilience for farmers because it has the potential to boost productivity and profitability along the value chain, improve access to financing, and address social inclusion gaps for youth and women. To fulfil the potential of digitalization, an enabling environment is required that allows suitable digital solutions to emerge and to be adopted effectively as part of a broader toolbox of measures that can transform African agrifood systems. This chapter explains the four pillars of digitalization for agriculture (D4Ag) and takes a closer look at two of those pillars that are required to build a strong enabling environment.

\section{What Is Digitalization for Agriculture?}

D4Ag holds great promise for the transformation of African agriculture, but only if it is carried out holistically-that is, if it is well defined and appropriately deployed as part of broader agricultural and rural development strategies. In other words, digitalization must be understood as an agricultural development tool rather than a technological tool so that its application is problem- rather than technology-driven.

Tsan et al. (2019) define D4Ag as the use of digital technologies, innovations, and data to transform business models and practices across the agricultural value chain and address bottlenecks in, among other things, productivity, postharvest handling, market access, finance, and supply chain management so as to achieve greater income for smallholder farmers, improve food and nutrition security, build climate resilience, and expand inclusion of youth and women. The concept of D4Ag can be illustrated through four pillars: (1) digital agricultural innovations, (2) big data and analytics, (3) business development services, and (4) the enabling environment (Figure 13.1). These four pillars can be applied to any agricultural transformation issue or challenge, including climate variability, low productivity and profitability, inaccessibility of financing, and exclusion of social groups, among others. While the chapter focuses on the third and fourth pillars, that is, enabling environments for $\mathrm{D} 4 \mathrm{Ag}$ business development and the adoption of D4Ag solutions in Africa, it will also briefly outline the other components to provide context for the chapter.

Pillar 1: Digital agricultural innovations. According to the Global Innovation Index 2017, digital innovation in agriculture has been relatively slow, and leading global digital technology companies have made few inroads into agriculture. These innovations are being championed by "Big Ag" companies, small start-ups, smaller agricultural technology (agtech) companies, governments, mobile network operators, and top agricultural universities. They can be divided into "digital technologies" and "digital solutions and services." Digital technologies may include infrastructure (cables, masts, wireless routers, etc.) and hardware (mobile phones, sensors, blockchain, drones, etc.) required to operate, offer, and access digital services and solutions (Trendov, Varas, and Zeng 2019). Digital agricultural solutions and services, in contrast, encompass services and products offered to end users with the support of digital technologies (Malabo Montpellier Panel 2019). Tsan et al. (2019) provide a comprehensive analysis of 


\section{FIGURE 13.1—FRAMEWORK FOR DIGITALIZATION IN AGRICULTURE}

\section{Support Digital Agricultural Innovations}

1. Digital agricultural technologies

2. Digital agricultural solutions and services

3. Identification, development, and promotion of access

4. Promote Enabling Environment

1. Digital strategies / infrastructure

2. Nondigital—transport, energy, etc.

3. Knowledge exchange and networking

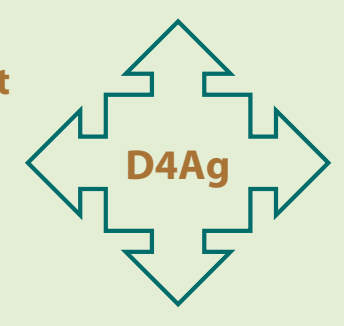

2. Enable Big Data and Analytics

1. Reliable content for digital solutions

2. Digital identities / farmer registries

3. Remote sensing satellites, drones, etc.

Source: Compiled by Benjamin K. Addom.

\section{Facilitate Business Development Services}

1. Digital entrepreneurship-incubation, coaching, etc

2. Digital literacy and skills for agriculture

3. Business linkages and networks

the current state of D4Ag in Africa. They find that the availability of D4Ag solutions and services across the continent has skyrocketed, increasing from about 42 solutions in 2012 to more than 390 active solutions as of early 2019. However, overall, the market remains largely untapped, as many services are still small in scale, scattered, and not financially viable. These solutions and services need an enabling environment that will allow agricultural stakeholders to improve productivity, income, access to financing, supply chain management, and policy- and decision-making.

Pillar 2: Big data and analytics. Big data has been defined as large datasets that can be analyzed computationally to reveal patterns, trends, insights, and associations, especially in relation to human behavior and interactions (McAfee and Brynjolfsson 2012). For smallholder digital agriculture, varied sources of data covering two main areas-quality content and user identity-are key for change. Providing reliable and authentic agricultural content is one of the challenges affecting the performance of digital agricultural solutions (CTA 2018). The quality of agricultural data is currently being driven by remote sensing tools such as satellites, drones, sensors, the Internet of Things, and other sources of data. However, data on the users of digital agricultural solutions-actors along the value chain-has been missing (USAID 2018). Creating digital identities or farm registries for these actors can help solution providers identify their interests, behavior, and history and develop tailored and customized services for them. When varied data sources covering these two components-content and user data-are brought together and analyzed, the resulting insights can be used to improve the quality of solutions and advice to users. To support smallholder agriculture transformation across the continent, big data and analytics must be increasingly enabled through access to relevant and diverse sources of data that can be used for computational analysis and the development of customized advice to users. 
Big data and analytics are increasingly becoming an alternative approach to ensuring the sustainability of business models for digital solutions and services (Addom 2018). A functional data infrastructure is needed that combines user and content data to provide value for agribusinesses such as input manufacturers, aggregators, financial institutions, and so on, while allowing them to deliver free or subsidized digital solutions to farmers. For example, financial service providers need to know farmers and the locations of their fields for loan or credit services (Rabobank Foundation 2018). These user databases, when built accurately, can be accessed through digital platforms delivering agricultural advisory services and solutions. Also, index-based insurance services are being provided to farmers based on the historical data of their fields obtained via remote sensing technologies.

Pillar 3: Business development services. For digital solutions to be sustainable, there must be continuous investment either through payments by users or some other form of external funding to support service provision (Lohento and Tossou 2018; GSMA 2019). The limited adoption, use, and scale of digital solutions for agriculture has been reported in Tsan et al. (2019). These solutions have been developed through donor funding, development projects, self-funding, or large or small private sector investors. Entrepreneurs involved in the provision of the services must be prepared to manage service growth and development in a way that ensures sustainability. Since smallholder farmers are generally not willing or able to pay for information services driven by digital innovations, efforts must be made to explore models that encourage other stakeholders such as cooperatives, input dealers, financial institutions, governments, nongovernmental organizations, retail organizations, and commercial farmers to pay for these services. This shift will take place when the value being obtained from these services is enhanced such that third parties other than smallholders will be willing to contribute financially. In addition, there is a need to build the business capacity of service providers, particularly start-ups, through incubation, coaching, business linkages, and networking to prepare them to face future business challenges.

Pillar 4: Enabling environments for digitalization to thrive. The enabling environment includes policies, institutions, infrastructure, support services, and other conditions that create a business setting in which enterprises and business activities can start, develop, and scale (Christy et al. 2009). This environment includes the "rules of the game" that are established to achieve a sustainable balance between social, economic, and environmental needs. The enabling environment within the context of digital agriculture should therefore embody a set of interrelated conditions that together facilitate the smooth and continuous inclusion of actors within the agricultural ecosystem through strategies, policies, and other enablers of sustainable agricultural development. Ohiomoba (2013) argues that an enabling environment for information and communications technologies (ICTs) in agriculture in African, Caribbean, and Pacific countries is one in which policies and practices as well as infrastructure and general investments are favorable for ICTs to thrive and positively contribute to agricultural improvements.

In the absence of an enabling environment, developing and scaling suitable digital technologies and services for agricultural stakeholders will not be possible; using modern tools to capture and offer quality data and content for the digital solutions will be inadequate; and engaging and deploying innovative and viable business models will not suffice to transform agriculture. The enabling environment includes both digital and nondigital factors that support digitalization. The following section describes some of the critical factors that will determine whether and how an enabling environment for digitalization in agriculture will emerge across the continent.

\section{Factors Determining the Enabling Environment for D4Ag Businesses and Adoption}

\section{Strategies and Policies}

Digital innovations continue to multiply despite the absence of sound sector policies and strategies to guide their development and deployment. While the lack of sector policies may not necessarily be an impediment to the current growth of D4Ag, investment readiness, long-term sustainability, and large-scale adoption of viable solutions may still be an issue. Well-developed national and/ or regional digital agricultural policies and strategies may outline procedures for the development of digital platforms, D4Ag infrastructure, implementation of D4Ag projects, the operations of private sector service providers, enforceable or advisory guidelines by governments for users and implementers, and a code of conduct for all actors.

Driven in part by the United Nations Economic Commission for Africa (UNECA) through the National Information and Communication 
Infrastructure (NICI) framework developed in 2000, African countries across the continent have made significant progress in developing and implementing national ICT policies and strategies (UNECA 2007). While UNECA focused on national ICT policies and plans, national governments identified key priority areas, usually referred to as pillars, including ICTs for agriculture. The World Summits on the Information Society in 2003 and 2005 called for the development of ICT strategies for all sectors, referred to as e-strategies. Accordingly, several countries have moved from policy formulation to implementation in sectors such as government services, education, health, and agriculture.

Within the agricultural sector, e-strategies are still lacking or not as comprehensive as they should be. The Technical Centre for Agricultural and Rural Cooperation has been one of the champions of e-agriculture strategies, offering technical support to African, Caribbean, and Pacific countries to develop and implement their sector strategies. The Food and Agriculture Organization of the United Nations and the International Telecommunications Union jointly developed a National e-Agriculture Strategy Guide in 2016 (FAO and ITU 2016). The guide identified three key components in the development of a national e-agriculture strategy: (1) the vision development process, (2) action plan development, and (3) a monitoring and evaluation component. The guide concluded that the development of a national e-agriculture strategy is only the first step toward realizing the transformative potential of ICTs in agriculture. It maintains that the strategy must be implemented to realize the transformative power of the technologies, and, most importantly, the strategy must be reviewed periodically to ensure that it keeps up with changing demands, emerging goals, and new technologies.

These early sector strategies and policies make little or no mention of emerging digital technologies such as big data and analytics, blockchain, the Internet of Things, robotics, machine learning, artificial intelligence, drones, satellite data, and their implications for agricultural development. In light of the fast-changing landscape of digital technologies and services, these sector strategies, most of which were developed in the mid- to late 2000s, need continuous updating to meet the demands of the sector. An example of such an update can be seen in Rwanda, where NICI I, developed in 2000, was updated to NICI II in 2006 and NICI III in 2010 to keep pace with the developments within the sector.
At the same time, the country's ICT Sector Strategic Plan (2013-2018) has been expanded into the National ICT4RAg Strategy (2016-2020). This strategy is intended to serve as guide to ensure appropriate use of digital solutions, data, and business development services to benefit Rwanda's citizens.

Policy recommendation: Strong foundations have been laid by regional and national bodies. To keep up with changing demands, emerging goals, and new technologies, individual countries must endeavor to continuously review their strategies to address current issues and innovations within the sector. The example of Rwanda should be emulated. In addition to the currently widespread mobile-phone-enabled solutions, focus must also be placed on policies to monitor and regulate the deployment of emerging digital technologies that, in the longer term, have the potential to transform smallholder agriculture across the continent.

\section{Literacy and Skills}

Digital literacy and skills are needed for the development, adoption, use, and scaling up of digital solutions in agriculture (Trendov, Varas, and Zeng 2019). The ability of agricultural stakeholders to access, manage, understand, integrate, communicate, evaluate, and create information safely and appropriately through digital technologies is paramount. Conversely, the absence of digital literacy and skills stands in the way of effective implementation of these new technologies. Limited knowledge and skills in using ICTs by farmers contribute to the challenges in adoption (Abdullah 2015; Mulauzi and Albright 2008). In the short term, the skills to use mobile phones in particular will need to be strengthened, since the Internet and digital agricultural services are primarily accessed through these devices (Gillwald and Mothobi 2018; Tsan et al. 2019). In the medium to long term, skills to take advantage of more advanced emerging digital technologies will also be needed.

Information about the digital literacy of D4Ag target users in Africa is limited. Data from the Research ICT Africa (RIA) Beyond Access survey in $2017 / 2018^{1}$ show that a lack of conventional literacy, that is, whether someone is able to read or write, is not necessarily an obstacle to mobile phone ownership. Survey data from a number of African countries show that illiterate users make up a sizable share of mobile phone owners, including both those who

1 The data are available at https://researchictafrica.net/data/after-access-surveys/. 
obtain income from agricultural activities and those who do not (Figure 13.2). The data also show, however, that levels of illiteracy are clearly higher among those who do not own mobile phones, although the direction of causality is difficult to establish. Only about a third of the small number of smartphone users responding to the survey in Ghana and Nigeria had ever installed an application on their phone, compared to 44 percent in Senegal, 51 percent in Kenya, and just 12 percent in Rwanda. These shares generally decrease with an increasing reliance on agriculture as an income source.

Feder, Richard, and Zilberman (1985) found that educated farmers tend to be early adopters of technology and apply the associated inputs more effectively. For digital technology users such as smallholder farmers, researchers, traders, extension agents, policymakers, and so on, information and data literacy are key. A systemic literature review carried out by Heideveld (2019) on digitalization and agriculture found that use of ICTs is dependent on the literacy of the people. Skills for managing data-browsing, searching, filtering, assessing, and evaluating data, information, and digital content-are paramount. Additionally, skills in digital communication and collaboration, such as interacting with others, sharing content, and managing digital identity, are critical. Going beyond the basics, users must be able to use digital technologies and tools to solve social,
FIGURE 13.2-LITERACY LEVELS AMONG MOBILE PHONE OWNERS AND NON-OWNERS, BY DEPENDENCE ON AGRICULTURE

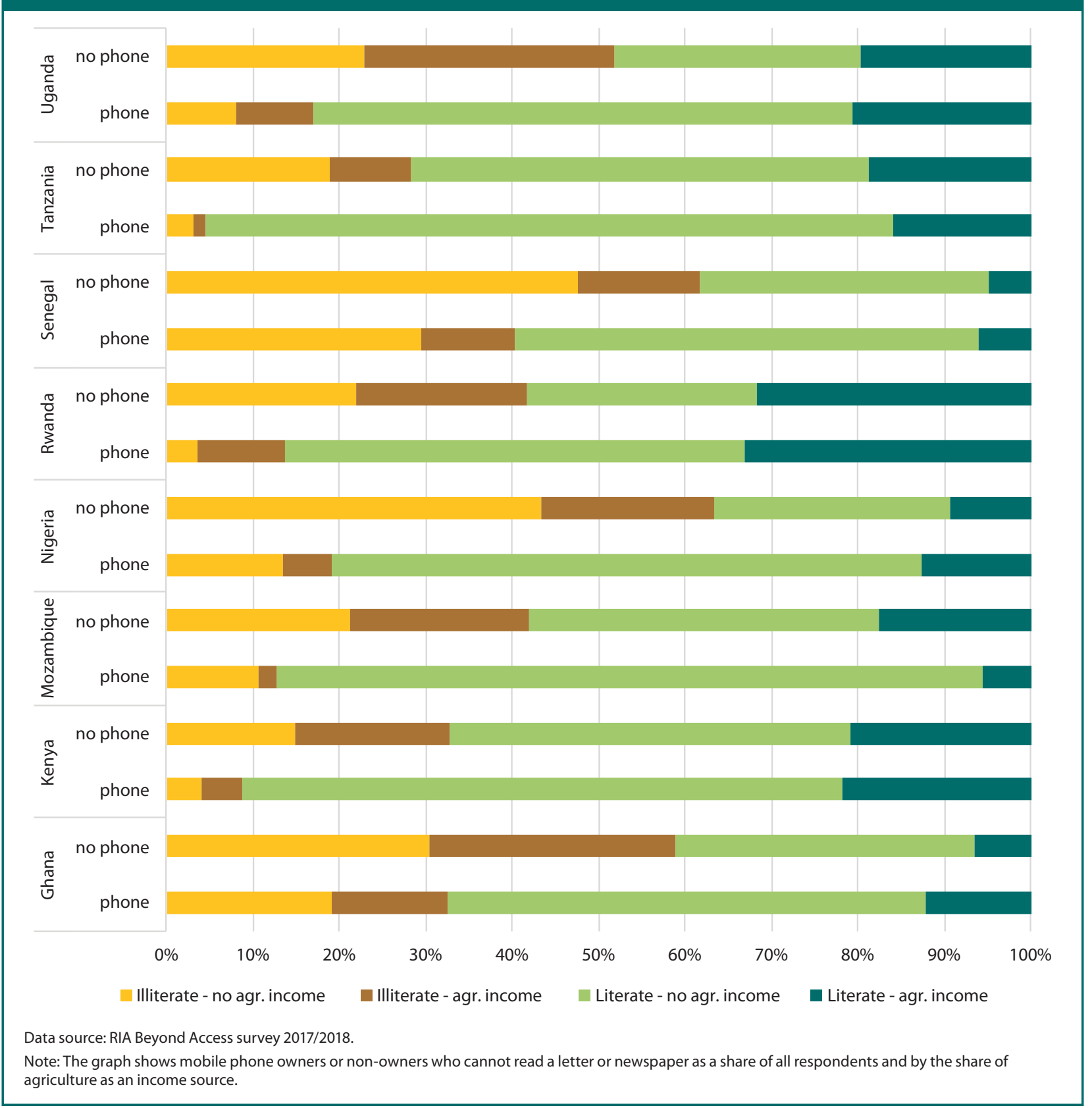


developmental, and technical problems. Taken together, all these are skills that allow users to creatively solve issues. Also critical are knowledge and skills to ensure digital safety, such as by protecting devices, personal data and privacy, and health and well-being.

For smallholder farmers and traders specifically, there is a need to identify regular operations that require digital literacy and skills to perform, including simple tasks such as turning a device on and off and charging it; sending and receiving text messages; setting or changing an app language; sharing location data or images of field situations; creating a public profile; searching for, choosing, downloading, and approving the privacy policy of an app; performing intra-app financial transactions; searching for goods and services and comparing price information; interacting with buyers and sellers; and topping up accounts through agents, among many others. In addition, reaching smallholder farmers may require engaging intermediaries such as extension agents, agrodealers, or community leaders to assist them in using digital solutions. Young people can also play an important role as intermediaries by assisting their family and other community members in accessing digital agricultural services.

For digital agricultural solution and platform developers, literacy in the areas of technical programming, content creation and integration, copyright and licenses, and so on, is key. The success of a given platform also depends on the business skills of the team. Hence, platform developers must have team members who are able to develop a business model or case around the products for deployment. Building these skills will require reform of many African countries' formal education and training systems by introducing digital skills from primary through tertiary education. Outside formal educational systems, on-the-job digital training can help "digital migrants" cope with the changing professional system.

Policy recommendation: Digital inclusion depends on digital literacy and skills, and literacy is an important consideration in a broader definition of access. African countries need to integrate digital education into the curricula of schools, universities, and vocational training institutes and improve regular on-the-job training of users to support rapid adoption and effective use of digital technologies and solutions. Care must be taken to ensure that the resulting digital skills are in line with the demand of the labor market and can help entrepreneurs grow their businesses.

\section{Knowledge Exchange and Networking}

Knowledge exchange and networking are critical factors in providing an enabling environment for D4Ag to thrive, as they form the basis for exchange of information on the other three pillars of D4Ag. Agricultural stakeholders, including those in the D4Ag domain, need to be kept up to date on changes within the sector. This can only be done through knowledge exchange and networking. The current state of D4Ag in Africa is marked by weak mechanisms for managing digital innovations, unreliable data and knowledge products, lack of business linkages and knowledge flows, and limited sectoral coordination, resulting in missed opportunities for collaboration and leading to duplication of effort (Tsan et al. 2019).

The D4Ag sector needs robust knowledge products and services that inform the various actors within the ecosystem, such as a "knowledge and innovation hub" that liaises between all players. The hub should act as an honest knowledge broker to facilitate knowledge sharing and networking among stakeholders. This can be achieved through consistent data gathering, curation, validation, and sharing. A comprehensive database that pulls datasets from varied partners and sources, such as donors, implementers, enterprises, researchers, farmers, etc., and can analyze them computationally to derive added value for all the contributing partners. The outcome will be regular access to quality processed knowledge products such as reports, discussion papers, technical briefs, and policy pointers that provide the sector with trends, insights, and challenges for relevant actors to act on. Knowledge exchange must be based on data-data management systems that provide evidence, market intelligence, and impact for better decision-making.

Networking is key to partnership building, which facilitates access to data, funding, and other opportunities across the entire value chain of stakeholders. Lack of linkages and knowledge flows limits sector coordination, resulting in duplication of effort. Strong and functional global, regional, and national communities of practice form a solid foundation for networking among agricultural stakeholders. Face-to-face conferences, expert workshops, webinars, and other in-person or digital meetups provide a good platform for networking. Networking and cross-country learning through South-South and North-South collaboration provide solid ground for expansion of D4Ag. Thematic e-discussions, funding news, global alerts, and referral programs help bring together fragmented initiatives. 
Networking platforms-whether virtual or face-to-face-can provide coordination mechanisms for stakeholders in the ecosystem to ensure efficient use of scarce resources. These platforms connect entrepreneurs to investors, users to developers, smallholder farmers to commercial farmers, small enterprises to big technology companies, and researchers to policymakers, among other linkages. They ensure experience sharing among actors. Through networking, cutting-edge innovations from developed countries can be shared and adapted for use by smallholder farmers and other stakeholders. Focused networks can be built to identify, test, and monitor emerging technologies in partnership with technical experts from across the globe.

Policy recommendation: The digital agricultural knowledge space is characterized by duplication of scattered knowledge products and resources. This situation does not support quality knowledge sharing among agricultural stakeholders. Thus, the sector should explore and embrace a centralized "knowledge and innovation hub" that liaises between all players. The hub should act as an honest knowledge broker to facilitate knowledge sharing and networking among stakeholders. The hub can also support data gathering, curation, validation, and sharing through a comprehensive database that pulls and analyzes datasets from varied partners and sources.

\section{Infrastructure Provision and Access}

Infrastructure investments are a prerequisite for both the provision of and access to D4Ag services. The presence of mobile network coverage is not sufficient in this regard, however. Equally important are quality and affordability as well as equitable access. While progress has been made with regard to network coverage and physical infrastructure, shortcomings related to the other aspects are still hindering effective use of digital infrastructure and consequently the ability to offer digital services to agriculture actors-smallholders in particular.

The cable infrastructure in Africa has improved in recent years. International connectivity through undersea cables has expanded significantly. ${ }^{2}$ The area and population connected by fiber-optic cables is also growing. ${ }^{3}$ By 2019, 584 million people (or 55 percent of the population of Africa south of the Sahara) lived within a 25-kilometer range of an operational fiber-optic network node, compared to 259 million in 2010 (Hamilton Research 2019). However, major gaps in the terrestrial infrastructure remain. As a result, international connectivity is not necessarily used at full capacity. In Nigeria, for instance, it is estimated that less than 10 percent of sea cable capacity is actually used (Eleanya 2019).

One of the main challenges today is covering the "last mile" to allow end users to cost-effectively access mobile networks and the Internet. Addressing this gap is partly a question of infrastructure, including innovative solutions such as wireless networks or WiBACK. In addition, even where there is broadband coverage, people do not necessarily use the Internet because they do not know what the Internet is or how to use it, or do not have access to the necessary devices (Gillwald and Mothobi 2018). While 60 percent of the population south of the Sahara is covered by broadband, and therefore could use it in theory, only around one-third of people are actually using the Internet (GSMA 2018).

Beyond the extent of mobile networks, other important factors that determine the utility of mobile infrastructure are the speed of the connection, the cost of using mobile services, and social norms that affect access to mobile handsets or the Internet. In terms of speed, Africa has the worst fixed broadband performance in the world, though its mobile broadband performance is comparable to that of South America and Asia (McKetta 2019).

The cost of handsets has dropped significantly in recent years as companies increasingly develop cheaper phones targeted at lower-income users. Government policies have also contributed to this cost reduction in some countries. In Kenya, for instance, the government lowered taxes on handsets to reduce costs (Schumann and Kende 2013). The cost of mobile use has also dropped, including mobile cellular and mobile broadband (Table 13.1), although costs differ widely among countries. Despite the decrease, a survey in seven African countries showed that among Internet users, 36 percent cited high costs as the main barrier to using the Internet (Gillwald and Mothobi 2018). Interestingly, only 15 percent of Internet users cited speed as a main barrier, though this could be because almost two-thirds of Internet users are located in urban areas.

Importantly for the provision of D4Ag services, rural-urban divides persist across Africa. Fiber-optic cables are usually better developed in urban areas because urban markets are more lucrative for mobile network operators. The quality of mobile networks is comparably worse in rural areas, which suffer from slower speeds and weaker connections. People often have several SIM cards

2 See www.submarinecablemap.com.

3 See https://afterfibre.nsrc.org. 
TABLE 13.1-COST OF MOBILE-CELLULAR AND BROADBAND BASKETS IN AFRICA

\begin{tabular}{|l|c|c|c|c|c|c|c|c|}
\hline & \multicolumn{4}{|c}{ Mobile-cellular basket } & \multicolumn{3}{c|}{$\begin{array}{c}\text { Mobile-broadband basket, prepaid } \\
\text { handset-based (500 MB) }\end{array}$} \\
\cline { 2 - 10 } & \multicolumn{2}{|c|}{$\%$ of GNI p.c. } & \multicolumn{2}{|c|}{ PPP\$ } & \multicolumn{2}{c|}{$\%$ of GNI p.c. } & \multicolumn{2}{c|}{ PPP\$ } \\
\hline & 2008 & 2017 & 2008 & 2017 & 2013 & 2017 & 2013 & 2017 \\
\hline Average & 27.6 & 14.3 & 40.3 & 21.7 & 23.8 & 10.1 & 40.4 & 16.3 \\
\hline Minimum & 1.3 & 0.6 & 12.3 & 4.7 & 1.4 & 0.7 & 10.5 & 5.9 \\
\hline Maximum & 86.9 & 58.1 & 73.1 & 55.1 & 132.0 & 53.3 & 268.4 & 57.3 \\
\hline
\end{tabular}

Source: ICT Price Basket, ITU, www.itu.int/net4/ITU-D/ipb/

Note: GNI p.c. refers to gross national income per capita.

so they can use whichever network is available at a particular location. As a result, rural-urban Internet usage gaps are significant, for instance, 87 percent in Mozambique and 36 percent in South Africa (Gillwald and Mothobi 2018).

To address these gaps, investments are needed to improve connectivity infrastructure and related services in underserved areas or for underserved groups. Smallholders constitute a large share of those who require such investments. One measure being implemented in several African countries is universal access (or service) funds, which can be funded, for example, by levies on licenses, a percentage of telecom operators' gross revenues, or grants or donations. In Kenya, funds were used to finance $2 \mathrm{G}$ coverage in un(der)served areas and broadband connectivity in public learning institutions. ${ }^{4}$ Of the 37 funds that exist in Africa, only 23 appear to be active (WWW Foundation 2018). Disbursement of funds is often a problem, however. It is estimated that around US $\$ 408$ million in such funds in Africa may still be unspent (WWW Foundation 2018).

Other measures to extend the range and reduce the cost of connectivity include legal requirements to share infrastructure, which reduces the establish ment costs for mobile network operators and thereby incentivizes investments in more remote or less populated areas, for example, by sharing network assets (masts, ducts, antennas, transmitters, or rights of use) or jointly building and operating infrastructure (Garcia and Kelly 2015). Infrastructure may also be shared between sectors, for example, in Kenya, where the state-owned electricity company allowed operators to deploy fiber-optic cables on its transmission infrastructure (Schumann and Kende 2013). In addition, public-private partnerships can reduce costs for private operators by co-financing infrastructure, as, again, in Kenya, where the government co-invested in an Internet exchange point and submarine and terrestrial cables (Schumann and Kende 2013).

Even perfect infrastructure will not be sufficient, however. Social norms also influence actual usage, though most of their impacts are not well documented. Some data are available with regard to gender disparity from the RIA Beyond Access survey 2017/2018. In terms of mobile phone ownership, the gender gap has narrowed in some African countries but remains large in, for example, Mozambique and Uganda. The divide with regard to Internet use is more significant, ranging from 13 to 48 percent in the countries shown in Figure 13.3. The urban-rural disparity often outweighs gender disparity, however. The RIA survey showed that in the seven countries surveyed, women in urban areas were more likely to own a mobile phone ( 42 percent) and use the Internet (19 percent), compared to men in rural areas ( 29 percent and 8 percent, respectively).

For D4Ag to reach smallholder farmers, it is also important to understand phone types and usage patterns among those who depend on agriculture. Data from Ghana, Kenya, and Nigeria show that smartphone ownership decreases with the level of dependence on agriculture as a source of income (Figure 13.4). These low smartphone adoption rates in turn will limit the sophistication of digital services that can be offered. It is interesting to note that the prevalence of feature phones differs quite widely, with particularly high ownership rates in Nigeria. The types of Internet activities are broadly comparable, irrespective of the dependence on agriculture. The main uses are social networking (approximately 30 percent) and education ( 25 percent).

It is important to note that digital technologies can only bring the promised benefits to agriculture if the context in which they operate is conducive. ICTs will need support infrastructure, including the electricity required to power mobile networks and technologies. There are still serious limitations to electricity access, particularly in rural areas of Africa south of the Sahara, where only 22 percent of the population had access to electricity in 2017.5 Innovative, decentralized solutions, such as small-scale solar, wind, or water-based energy, play an important

4 See https://ca.go.ke/industry/universal-access/universal-access-overview/.

5 Data obtained from https://data.worldbank.org/. 
role in serving rural areas. The spread of mobile towers can incentivize investment in electricity infrastructure; the tower provides the base demand and the excess supply is distributed to the local community (Bhattacharyyaa and Palitb 2016).

In addition, for digital solutions to become an effective tool, the agricultural sector as a whole must be promoted. For instance, digital information services will not benefit farmers unless they are able to act on the information they receive, for example, by accessing inputs or connecting to different buyers. In addition to electricity, investment in transportation, irrigation, storage, and marketing will be vital. Most importantly, a coherent, overarching infrastructure plan will be needed to ensure that the various investments can complement each other.

Policy recommendation: Affordable and equitable access to well-functioning digital infrastructure is a prerequisite for D4Ag to scale. Countries should plan infrastructure so as to enable the use of not only today's but also tomorrow's emerging digital technologies and solutions. Governments should build public-private partnerships and make effective use of universal access funds to improve access for underserved areas and groups. This approach will promote infrastructure sharing and simplify licensing regimes to reduce the cost of digital access. Particular attention should be paid to ensuring access for women and marginalized groups. Importantly, digital infrastructure investments need to be accompanied by investments in other types of infrastructure, such as electricity, transport, and storage facilities, to improve the agricultural context overall.

\section{Access to Financing for D4Ag Service}

\section{Providers}

Despite the current progress in D4Ag service providers' ability to access financing, the percentage of investment in the sector is still very low compared to other sectors. Investment in Africa-based D4Ag start-ups in 2018 represented only 3-6 percent of all Africa tech start-up
FIGURE 13.3-MALE AND FEMALE MOBILE PHONE OWNERSHIP AND MOBILE INTERNET USE, PERCENT BY COUNTRY

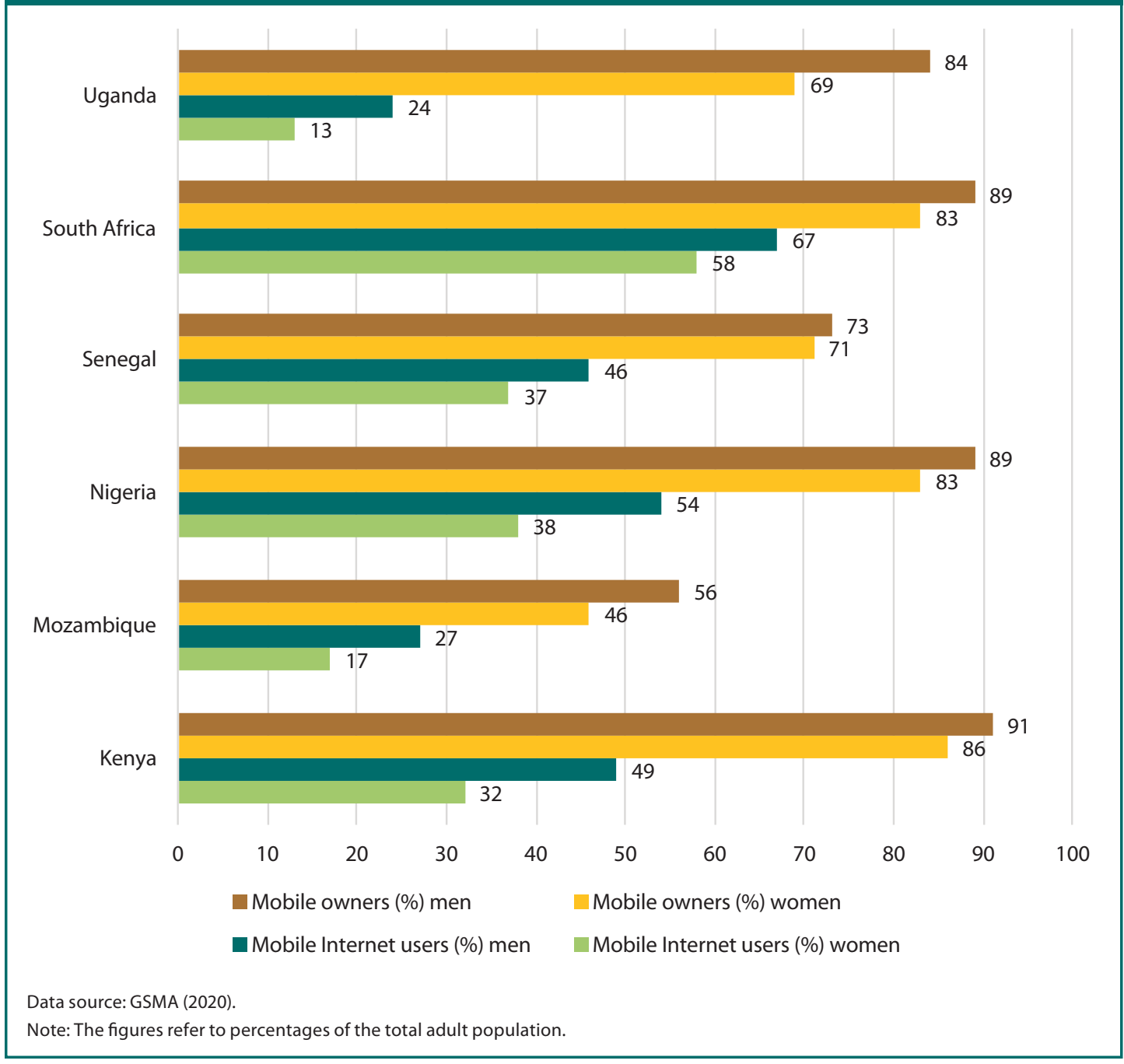

investment (Tsan et al. 2019). However, access to financing is crucial for effective D4Ag service provision, including start-up funding to develop the services, midlevel financing to move to scale, and revenue generation for long-term viability. 


\section{FIGURE 13.4-TYPE OF MOBILE PHONE OWNED, BY DEPENDENCE ON AGRICULTURE}

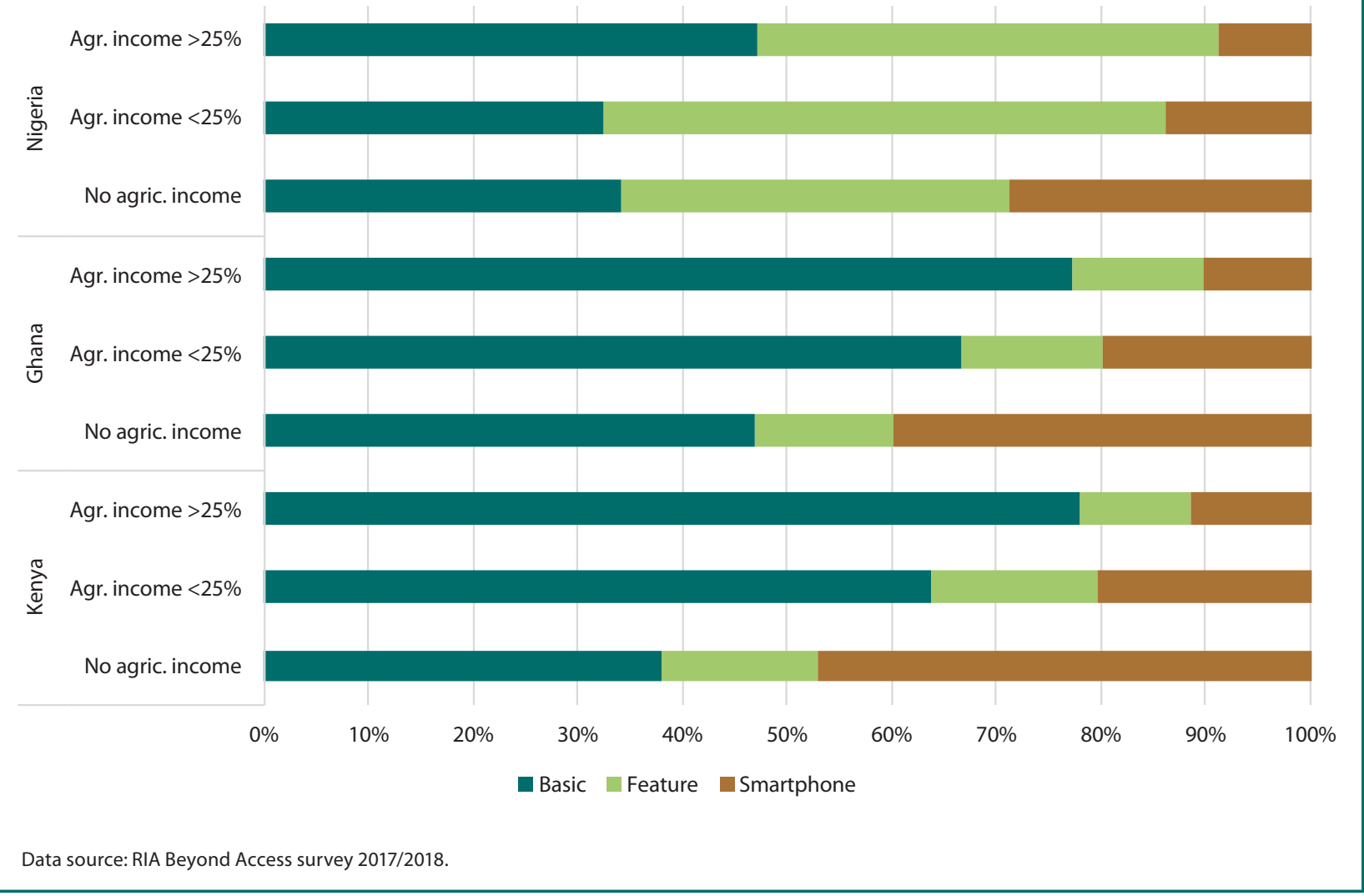

Opportunities to access financing exist in Africa for local start-ups, such as through angel investors who invest comparatively small sums and are willing to take risk. Additional financing can be obtained through competitions such as Pivot East, the largest event in East Africa for start-ups to pitch ideas for digital services and win seed funding. ${ }^{6}$ At the other end of the scale, larger-scale investments are being made through corporations. For example, the German software company SAP is investing in the development of supply chain management software to coordinate sourcing from smallholders, and the mobile network operators Orange $^{7}$ and Safaricom ${ }^{8}$ are setting up platforms that offer multiple services for different actors in the agricultural sector. However, what is often lacking is mid-level financing to help start-ups scale and develop into fully fledged businesses that can compete with the large players.

In the longer term, start-ups need business models that make them financially sustainable. Tsan et al. (2019) estimate that 70 percent of the 390 active D4Ag service providers in Africa generate some revenue, and 80 percent of those revenue-generating enterprises maintain several revenue streams. Financial viability is still rare, but it is improving. Among 175 surveyed enterprises, just 26 percent report that they are breaking even. The annual revenue generated per farmer amounted on average to $€ 5$ for advisory services, $€ 25$ for market linkages, and $€ 4$ for digital financial service intermediaries and supply chain management solutions. Some companies are able to achieve $30-40$ percent gross margins. The availability of digital payment systems has also helped greatly in generating financial returns from digital services, for example, through online banking or mobile payments. This is also one of the reasons why such services have expanded rapidly in Kenya. The mobile money transfer service M-Pesa is widespread even in rural areas and allows service providers to include financial transactions in their services.

A focus on farmers as the target beneficiaries will make it difficult to generate significant revenue unless they can be reached at a very large scale. Alternative

6 See https://pivoteast.co.ke/.

7 See https://hellofuture.orange.com/en/innovative-services-that-are-supporting-agriculture-in-africa/.

8 See www.safaricom.co.ke/business/digifarm/what-is-digifarm/digifarm. 
models include cross-subsidizing lower-income customers with premium services sold to higher-income customers or targeting wealthier actors higher up in the value chain with spillover effects to benefit farmers. In addition, where digital services are part of larger operations, the main economic rationale may no longer be income generation from the service, but rather other gains, for instance, the introduction of digital supply chain management tools to reduce transaction costs, increase efficiency of business operations, and ensure the reliability of high-quality supply.

Policy recommendation: Considering the enormous potential of digitalization for the agricultural sector, a coordinated approach to financing and investment is recommended. National governments need to coordinate with donors, foundations, and private sector investors on phased investment in the sector. Donors and foundations should absorb the risks associated with the development and pilot testing of the technologies and services, while national governments provide the necessary investment incentives. The private sector will then build upon the tested innovations to scale them for commercial purposes, with the possibility of subsidizing the services for underserved communities.

\section{Business Ecosystem for D4Ag Service Providers}

Creating an enabling business climate for entrepreneurs is a key condition for success. Skills for digital service providers and users; access to financing; and well-functioning, affordable infrastructure were already discussed above. Other elements of the ecosystem include innovation hubs, networks, and a conducive business environment. These elements are not unique to agriculture but are required for any business sector to emerge and grow. However, an "agriculture lens" is needed when designing related business support policies to ensure that rural areas are not neglected and that the differing financial, educational, and technological capacities of smallholder are taken into account.

Innovation hubs. Innovation hubs can provide a space for networking and mentoring, an entry point for investors, and deployment of publicly accessible small-scale workshops offering digital fabrication. The Kenyan iHub was among the main drivers of the establishment of such hubs across Africa. In 2019 there were 618 active tech hubs, with Nigeria and South Africa having particularly high concentrations (Giuliani and Ajadi 2019). ${ }^{9}$ Lagos, Nigeria; Cape Town, South Africa; and Nairobi, Kenya, are among the cities that host the most hubs. More than 50 percent of all hubs involve public or corporate partnerships, including with mobile network operators such as MTN, Orange, or Vodafone, as well as IT companies such as Nokia or Microsoft (Giuliani and Ajadi 2019). This applies to simple hubs as well as accelerators that actively assist promising start-ups.

Networks. Interconnection of the main actors in start-up ecosystems plays an important role in the development of local ecosystems that can support start-ups as they grow. This interconnection should also extend beyond African borders. Reinforcing cooperation between Africa and industrialized countries on mutually beneficial terms can help build bridges between start-ups in different parts of the world and therefore boost the emergence of joint projects; facilitate access to venture capital; and increase talent recruitment, creativity, and financing opportunities.

A conducive business environment. A conducive business environment includes legal predictability, positive fiscal policies providing incentives, and low levels of corruption. Figure 13.5 shows how selected countries are performing in terms of their ICT-related enabling environment for rural agriculture in relation to mobile connectivity. While it is not possible to establish causality between the two indicators, they show a positive and significant correlation $(r=0.7)$, highlighting the importance of a strong regulatory regime for technology adoption (Kayumova 2017).

Policy recommendation: A strong enabling environment, created through conducive regulations and investments, is critical to every business. Any measures to strengthen the private sector should pay particular attention to young start-ups, to enable them to scale proof-of-concept D4Ag solutions by providing them with a business environment that safeguards their investments. In addition, any enabling measures must be assessed-and, when necessary, amended-with a D4Ag lens to ensure that rural areas are well served through infrastructure and services, that innovation hubs offer mentoring and support for agriculture-related digital solutions, and that developers have access to innovative financial mechanisms in order to reach low-income customers, including smallholders.

9 A regularly updated map of innovation hubs is available here: https://africahubs.crowdmap.com/. 
Data, Content, and Access Rights At the continental level, efforts have been underway to harmonize and unify the system of data protection legislation. In 2014, the African Union (AU) adopted the African Union Convention on Cyber Security and Personal Data Protection, ${ }^{10}$ which addresses the need for data harmonization among member countries of the $\mathrm{AU}$, and mechanisms for each country to handle violations of data privacy (Box 13.1). As of July 2020 , only 8 out of the required 15 countries had ratified the convention (Angola, Ghana, Guinea, Mozambique, Mauritius, Namibia, Rwanda, and Senegal). According to Articles 11 and 12 of the convention, enforcement of legislation in individual countries would be undertaken through a national personal data protection authority (DPA), which would be responsible for informing the country's citizens of their rights and obligations with respect to data protection. The DPA would also ensure that the processing of personal data is consistent with the provisions of the convention.

A review of data protection legislation in 54 African countries by Chichaibelu, Matschuk, and Baumüller (forthcoming) found that among the 48 countries for which information was available, 27 have adopted data privacy legislation, 10 have included related revisions in other types of legislation, and 6 have drafts of legislation. Among the 27 countries with legislation, all except Nigeria, which has sector-specific agencies that manage data protection regulations, mention the establishment of a DPA under their data protection legislation. Of these 27 countries, 18 have the DPAs already established and operational, and 4 do not (for the remaining 5 the status is unknown). Among the countries in INDEX SCORES
FIGURE 13.5-CLUSTERING OF COUNTRIES ACCORDING TO THEIR EBA ICT AND MCI

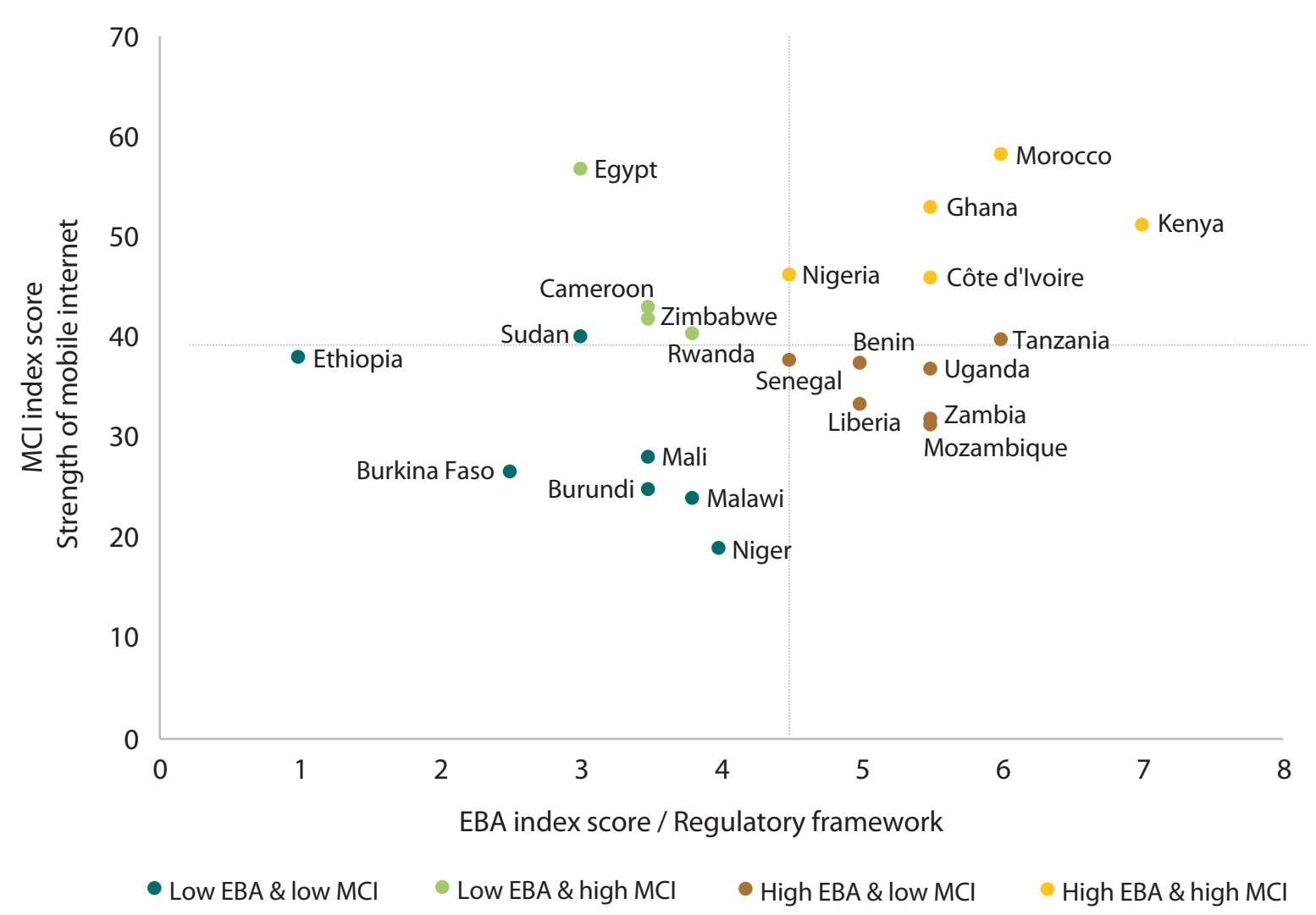

Source: Malabo Montpellier Panel (2019).

Note: The Enabling the Business of Agriculture (EBA) ICT Index measures to what extent laws, regulations, and policies relating to information and communications technology (ICT) promote an enabling environment for agriculture. The GSMA Mobile Connectivity Index (MCI) measures the key enablers of mobile Internet adoption, including infrastructure, affordability, consumer readiness, and content and services.

which DPAs have been set up, Mauritius and Morocco are reported to have wellestablished DPA programs (Rich 2017). Evidence of enforcement is also seen in Benin, Ghana, Mali, Senegal, and Tunisia (Rich 2017).

Part of the reason for the AU's push for harmonization between data protection policies in Africa is to ensure ease in data transfer between African

10 Available at https://au.int/en/treaties/african-union-convention-cyber-security-and-personal-data-protection. 


\section{BOX 13.1-KEY PERSONAL DATA PROTECTIONS OUTLINED IN THE AFRICAN UNION CONVENTION ON CYBER SECURITY AND PERSONAL DATA PROTECTION}

Principles governing the processing of personal data (Article 13 of the convention):

- Principle 1: Principle of consent and legitimacy of personal data processing

- Principle 2: Principle of lawfulness and fairness of personal data processing

- Principle 3: Principle of purpose, relevance, and storage of processed personal data

- Principle 4: Principle of accuracy of personal data

- Principle 5: Principle of transparency of personal data processing

- Principle 6: Principle of confidentiality and security of personal data processing

Data subject's rights (Article 16 of the convention):

- Right to information

- Right of access

- Right to object

- Right of rectification or erasure

countries. The analysis of related provisions in the enacted legislation shows that most countries do not require any authorization of data transfer to countries with an adequate level of data protection. Where the destination country does not offer an adequate level of data protection, data transfer is often allowed under certain conditions, for example, the individual's consent, contract obligations, and/or DPA authorization. Aside from these exemptions, countries such as Chad, Côte d'Ivoire, and Lesotho also grant special permission for cross-border transfers to countries that are members of specified regional economic communities.

To further understand the landscape of data protection and privacy policy in Africa, Chichaibelu, Matschuk, and Baumüller (forthcoming) conducted an online review of $211 \mathrm{D} 4 \mathrm{Ag}$ service providers that operate on the continent to gather information on the data that service providers collect on their users and whether they have a data protection policy. The review points to significant gaps in data privacy policies among digital service providers, even among those operating in countries with data protection legislation. Of the 211 providers, 82 have some form of privacy policy for their users. Among these providers, only 13 ask for permission to collect data and 26 communicate how the data collected are used. Thirty-three services share data with third parties, but only 14 ask for permission to do so.

Policy recommendation: Data are sometimes likened to oil or air. In other words, data are power. There is enormous potential to build data within the agricultural sector as a resource. However, a key component of this infrastructure involves the sensitive data of users-farmers and agribusinesses. The need to protect and ensure balanced use of this resource is critical. Over-regulation of such a resource will impede innovation within the sector, but, at the same time, lack of regulation can also lead to exploitation of some of the actors. African countries need to improve their data privacy protections at the national level and foster harmonization at the continental level. Countries also need to consider developing national data infrastructure that will provide the foundation on which private sector actors can build their digital services and solutions.

\section{Conclusion and Recommendations}

Digitalization can be a game changer for smallholders in the agrifood system in Africa. However, digitalization is a tool that needs to be positioned within a given context. Digitalization in support of the agrifood system, therefore, should be seen in terms of four pillars. In other words, new high-tech innovations can be developed, real-time remote sensing data and other sources of data can be built and made available, and a range of different viable business models can be developed, but without the appropriate enabling environment, the solutions 
and services will be short-lived. To be able to realize the transformational power of digitalization in African agriculture, all these interrelated conditions for an enabling environment must be fully embraced. However, the interplay between these conditions may differ from one geographic context to another at the national level, depending on the existing investments that have been made in these factors over the years.

Bearing in mind these national specificities, a number of priority steps need to be taken. First, at the continental level, decision-makers must reassess existing ICTs and agricultural policies and strategies and make efforts to continuously upgrade the digital space by considering new developments such as data to meet the demands of the agricultural sector. This should be done alongside the private sector, multinational development banks, and foundations and donors to upgrade the current infrastructure-both digital (connectivity, broadband, etc.) and nondigital (transport, energy, storage, etc.) - with the goal to provide easy and affordable services to rural communities. Second, with policies and infrastructure in place, the AU should embrace and promote phased financing of digitalization to ensure that innovations are de-risked through donor investments to support the long-term involvement of the private sector for sustainability. Third, a conducive business ecosystem, including a single continental market for goods and services, with free movement of persons and investments, must be ensured. Finally, continuous investment in capacity building, for digital literacy and skills as well as coordinated knowledge generation and exchange, will help support the sharing of best practices and the development of platforms for monitoring and ensuring the accountability of these investments, especially to the ultimate beneficiaries.

With visionary leadership at the continental level, transparent partnerships with multilateral institutions, and strong commitment at the national level, the collective impact of digitalization on African agriculture should not be a mirage but reality. 